\title{
Effect of long-term thermal exposure on microstructure and creep properties of DD5 single crystal superalloy
}

\author{
Xu-dong Wang 1,2, *Zhong Yang', Qiang Gao ${ }^{3}$ * *Li-rong Liu ${ }^{3}$ \\ 1. School of Materials and Chemical Engineering, Xi'an Technological University, Xi'an 710021, China \\ 2. Fugu County Xuli Mechanical and Electrical Technology Co., Ltd., Yulin 719499, China \\ 3. School of Materials Science and Engineering, Shenyang University of Technology, Shenyang 110870, China
}

\begin{abstract}
The effect of thermal exposure on the microstructure and creep properties of the Ni-based single crystal superalloy in different test conditions was studied. Long-term exposure was performed at $1,000{ }^{\circ} \mathrm{C}$ and $1,100{ }^{\circ} \mathrm{C}$ for $500 \mathrm{~h}$ prior to the creep tests. The creep lifetime is found to be improved after the long-term exposure at $1,000{ }^{\circ} \mathrm{C}$ for $500 \mathrm{~h}$ as a result of the formation of secondary $\mathrm{M}_{23} \mathrm{C}_{6}$ in the interdendritic region. The coarsening of $\mathrm{Y}^{\prime}$ precipitates accompanied by the formation of TCP phase lead to the degradation of alloy, which is responsible for the reduction of the creep lifetime of Ni-base single crystal superalloy after long-term exposure at $1,100^{\circ} \mathrm{C}$ for $500 \mathrm{~h}$. The creep lifetime of $1,000^{\circ} \mathrm{C}$ thermally exposed sample under the conditions of $1,093^{\circ} \mathrm{C} / 137 \mathrm{MPa}$ is lower than that of heat-treated state. Thermal exposure at $1,100{ }^{\circ} \mathrm{C}$ for $500 \mathrm{~h}$ causes the creep lifetime to drop drastically.
\end{abstract}

Key words: long-term thermal exposure; microstructure; creep properties; Ni-based single crystal superalloy; $\mathrm{M}_{23} \mathrm{C}_{6}$ carbide

CLC numbers: TG146.1 5 Document code: A Article ID: 1672-6421(2021)03-185-07

\section{Introduction}

Nickel-based single crystal superalloys are widely employed for hot sections of aircraft engines and gas turbines because of their excellent high temperature creep and fatigue strengths ${ }^{[1-3]}$. Single crystal superalloys are strengthened by high volume fractions of cubical $\gamma^{\prime}$ phase embedded coherently in $\gamma$ matrix phase, and by the addition of a variety of refractory elements ${ }^{[4,5]}$, such as $\mathrm{Re}, \mathrm{W}$ and Mo. The addition of refractory elements with higher melting points can enhance the solid solution strengthening and creep properties, but meanwhile, the freckles and precipitation of harmful phases may occur ${ }^{[6]}$. Adding a small amount of $\mathrm{C}$ element may form carbides, which can consume heavy refractory elements to reduce the probability of freckles and harmful phases formation ${ }^{[7,8]}$.

\section{*Zhong Yang}

Male, born in 1975, Professor. Research interests: aluminum magnesium light alloy and precision molding, and microstructure and properties of superalloys.

E-mail: yz750925@163.com

** Li-rong Liu

E-mail: Irliu@sut.edu.cn

Received: 2020-11-18; Accepted: 2021-03-29
During high-temperature service, the $\gamma / \gamma^{\prime}$ dual-phase microstructure will be degraded due to the coarsening process, which can lead to the degradation of mechanical properties. For example, long-term thermal exposure can cause $\gamma^{\prime}$ precipitates and $\gamma$ matrix in superalloys to coarsen ${ }^{[9,10]}$. Meanwhile long-term thermal exposure contributes to the precipitation of secondary TCP (topological close-packed) phases, such as $\mu$ phase, $\mathrm{P}$ phase. On the one hand, the existence of TCP phase may consume a lot of refractory elements, such as W, Mo and Re to weaken their solution strengthening effect in single crystal superalloy. On the other hand, brittle needle-like TCP phases can cause stress concentration during hightemperature service, which promotes the initiation and propagation of cracks along the TCP phase $/ \gamma$ matrix interfaces. In general, the creep lifetime of exposed samples decreases at different levels with increasing of aging time. The degeneration of creep properties is predominantly affected by the aggregation of $\gamma^{\prime}$ phase during thermal exposure ${ }^{[11,12]}$. For each single crystal superalloy, the high-temperature microstructural evolution and mechanical properties of alloy are main issues to which researchers pay close attention.

DD5 single crystal superalloy is a second-generation single crystal superalloy with $3 \mathrm{wt} . \%$ Re and $0.05 \mathrm{wt} . \%$ 
$\mathrm{C}$ addition, which shows excellent high temperature mechanical properties. The purpose of this study is to investigate the microstructural stability of DD5 alloy and creep properties after long-term thermal exposure $(500 \mathrm{~h})$. The coarsening behavior of $\gamma^{\prime}$ phase, precipitation of TCP phase and $\mathrm{M}_{23} \mathrm{C}_{6}$ carbide were investigated during long-term thermal exposure, and their roles in creep properties were also discussed.

\section{Experimental procedure}

Directionally solidified single crystal bars with [001] orientation with a diameter of $16 \mathrm{~mm}$ and length of $200 \mathrm{~mm}$ were produced in a vacuum directional solidification furnace. The longitudinal orientation of DD5 single crystal bars was determined to be within $7^{\circ}$ deviating from [001] orientation by means of EBSD (electron back scattered diffraction) method. The chemical composition of DD5 single crystal superalloy is listed in Table 1. Heat treatment of DD5 single crystal bars was performed according to the following standard procedure: $1,300{ }^{\circ} \mathrm{C} / 2 \mathrm{~h}$ (air cooling) $+1,100{ }^{\circ} \mathrm{C} / 4 \mathrm{~h}$ (air cooling) $+899{ }^{\circ} \mathrm{C} / 16 \mathrm{~h}$ (air cooling). The heat-treated bars together with small specimens were thermally exposed at $1,000^{\circ} \mathrm{C}$ and $1,100{ }^{\circ} \mathrm{C}$, respectively, for $500 \mathrm{~h}$.

Table 1: Chemical composition of DD5 single crystal superalloy (wt.\%)

$\begin{array}{cccccccccc}\text { Co } & \text { Cr } & \text { Mo } & \text { W } & \text { Al } & \text { Ta } & \text { Re } & \text { Hf } & \text { C } & \text { Ni } \\ 7.46 & 6.95 & 1.47 & 5.12 & 6.16 & 6.35 & 2.98 & 0.15 & 0.05 & \text { Bal. }\end{array}$

After heat treatment and $500 \mathrm{~h}$ thermal exposure at 1,000 and $1,100{ }^{\circ} \mathrm{C}$, respectively, single crystal bars were machined into $\mathrm{H}$-shaped creep test samples by electric wire-cutting machining. The gauge section of the test sheets was $4.0 \mathrm{~mm}$ in width, $2.2 \mathrm{~mm}$ in thickness and $20 \mathrm{~mm}$ in length, and the overall length of creep samples was about $40 \mathrm{~mm}$, as shown in Fig. 1. After grinding and mechanical polishing, constant load creep tests were conducted at $871{ }^{\circ} \mathrm{C} / 552 \mathrm{MPa}$, $982{ }^{\circ} \mathrm{C} / 248 \mathrm{MPa}, 1,038^{\circ} \mathrm{C} / 172 \mathrm{MPa}$ and $1,093{ }^{\circ} \mathrm{C} / 137 \mathrm{MPa}$ with the GWT504 creep testing machine. After creeping to fracture, the ruptured specimens were ground along the [001] direction to prepare a surface parallel to the [001] direction for microstructural observation. The samples were mechanically

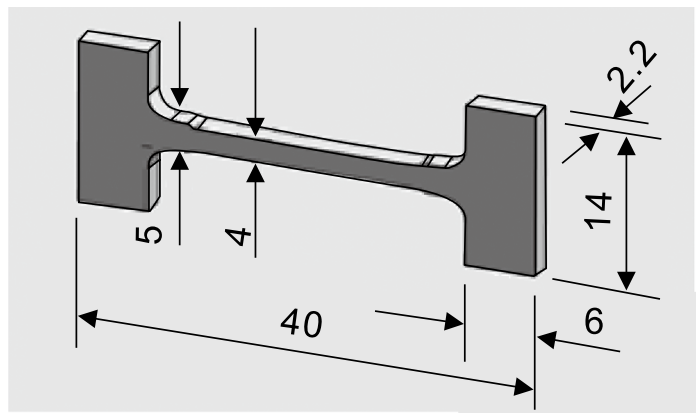

Fig. 1: Schematic diagram of creep specimen (unit: $\mathrm{mm}$ ) polished and etched with an etchant $\left(20 \mathrm{~g} \mathrm{CuSO}_{4}+100 \mathrm{~mL} \mathrm{HCl}\right.$ $+80 \mathrm{~mL} \mathrm{H}_{2} \mathrm{O}+5 \mathrm{~mL} \mathrm{H}_{2} \mathrm{SO}_{4}$ ). A Hitachi SU8010N field emission scanning electron microscope (FE-SEM) was used for microstructure observation. Before transmission electron microscopy (TEM) analysis, the samples were firstly cut into slices and ground to $50 \mu \mathrm{m}$ in thickness. A low-energy ion mill by liquid nitrogen cooling was used for thinning and cleaning of the specimens. TEM observation was performed using a high-angle annular dark field scanning transmission electron microscope (HAADF-STEM).

\section{Results and discussion}

\subsection{Microstructural evolution during long- term thermal exposure}

The microstructures of DD5 alloy after heat treatment and longterm thermal exposure are shown in Fig. 2. After heat treatment, $\gamma^{\prime}$ particles exhibit a uniform distribution in dendrite arm and cubical morphology with an average edge length of about 400 $\mathrm{nm}$. The $\gamma^{\prime}$ particles are aligned along $<100>$ direction and separated by $\gamma$ matrix channels with a mean thickness of about $50 \mathrm{~nm}$, as shown in Fig. 2(a). There are some primary MC carbides in the interdendritic region of the as-cast alloy due to the minor addition of carbon to DD5 alloy. After heat treatment, there are still some undissolved irregular MC carbides in the interdendritic region, as shown in Fig. 2(b), which are rich in Ta and Hf elements. $\gamma^{\prime}$ particles in the interdendritic region do not distribute uniformly as those in dendrite arm, and some subgrain boundaries consisting of $\gamma^{\prime}$ particles are found. The microstructure of the samples subjected to long-term thermal exposure at $1,000^{\circ} \mathrm{C}$ for $500 \mathrm{~h}$ is shown in Fig. 2(c, d). $\gamma^{\prime}$ phase coarsening and precipitation of TCP phase are clearly observed in the dendritic arm, and some $\gamma^{\prime}$ particles link to each other forming the strip-type morphology. In Fig. 2(c), the TCP phase (marked with yellow arrows) is surrounded by $\gamma^{\prime}$ phase and is not parallel or perpendicular to $<001>$ direction. There are still some irregular undissolved MC carbides, and some white block-shaped particles with a size of $400 \mathrm{~nm}$ precipitate along the sub-boundary in the interdendritic regions (marked with black arrows), as shown in Fig. 2(d). At the same time, some TCP phases (marked with yellow arrows) also precipitate in the interdendritic region.

In the specimen after long-term thermal exposure, the alloying elements experienced long-time diffusion to promote the growth of $\gamma^{\prime}$ phases and widen the $\gamma$ matrix channel. In addition, longterm thermal exposure can contribute to the interaction of various alloy elements, which may promote the formation of equilibrium phases ${ }^{[13]}$. Figure 2(e, f) shows the morphology of $\gamma^{\prime}$ phase after long -term thermal exposure at $1,100{ }^{\circ} \mathrm{C}$ for $500 \mathrm{~h}$ in the interdendritic region and dendrite arm. It can be found that in the dendrite arm region, $\gamma^{\prime}$ phase becomes continuous and irregular and some coarse TCP phases are found. In the interdendritic region, in addition to the coarse $\gamma^{\prime}$ phase, no second phases precipitate. Compared with the microstructure before thermal exposure, the microstructure after long-term thermal exposure 

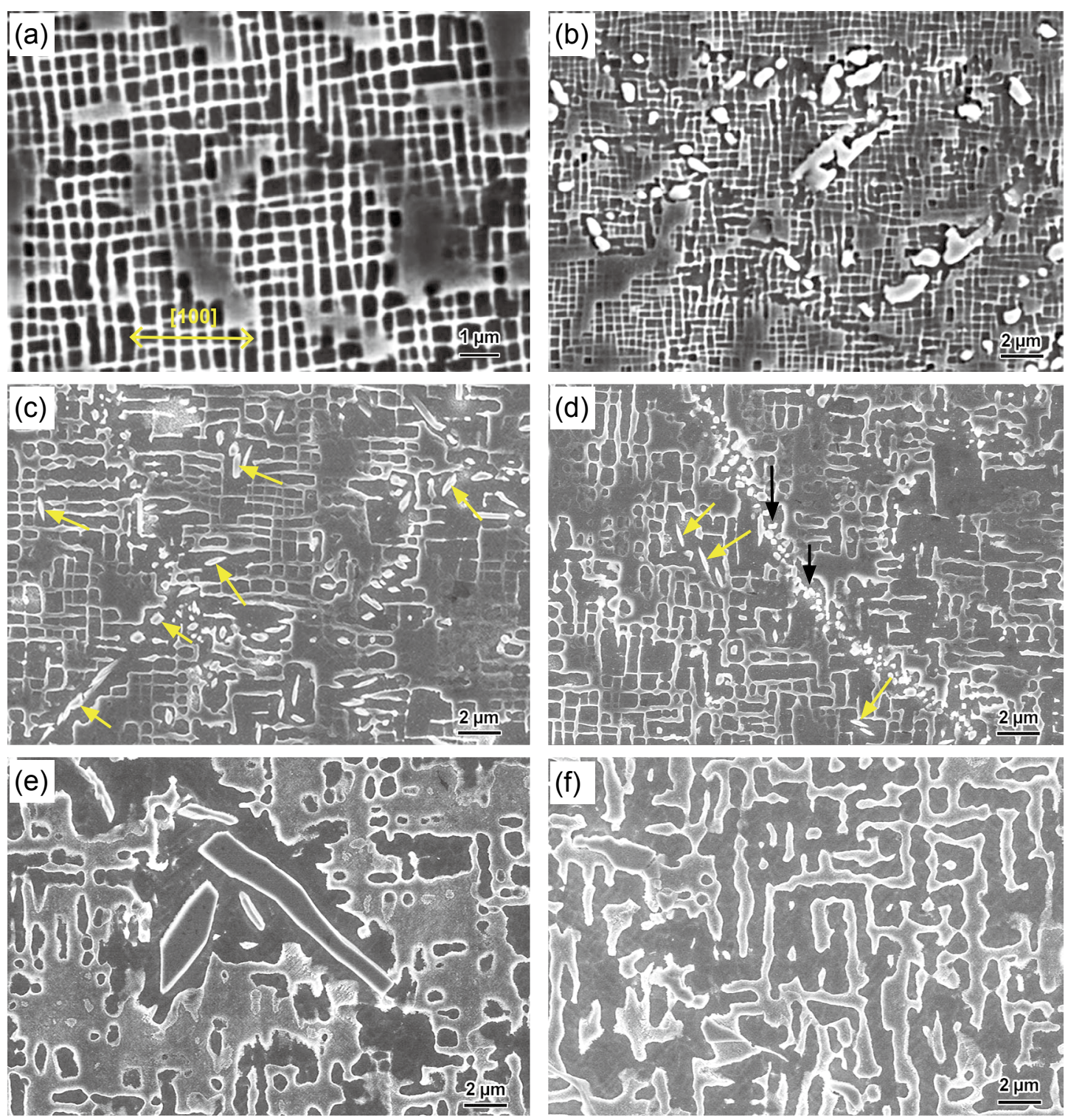

Fig. 2: Microstructures of DD5 single crystal superalloy at different states: heat-treated state in dendrite arm (a) and interdendritic region (b), thermal exposure at $1,000^{\circ} \mathrm{C}$ for $500 \mathrm{~h}$ in dendrite arm (c) and interdendritic region (d), thermal exposure at $1,100^{\circ} \mathrm{C}$ for $500 \mathrm{~h}$ in dendrite arm (e) and interdendritic region (f)

at $1,100{ }^{\circ} \mathrm{C}$ deteriorates so seriously that $\gamma^{\prime}$ phase gathers together, as shown in Fig. 2(e, f). EDS analysis shows that the granular phase in Fig. 2(d) is enriched in $\mathrm{Cr}$ and Re, as shown in Fig. 3(a); while the phase precipitated in the dendrite arm in Fig. 2(c) is mainly composed of Re, W and Mo [Fig. 3(b)]. Because the size of $\gamma^{\prime}$ particles is less than $1 \mu \mathrm{m}$, some peaks of other elements were detected.

\subsection{Creep properties}

Figure 4 shows the creep properties of DD5 alloy after heat treatment and long-term thermal exposure under different test conditions. Under the test conditions $\left(1,038^{\circ} \mathrm{C} / 172 \mathrm{MPa}, 982^{\circ} \mathrm{C} /\right.$ $\left.248 \mathrm{MPa}, 871^{\circ} \mathrm{C} / 552 \mathrm{MPa}\right)$, the creep lifetime of DD5 alloy at different testing conditions shows the same tendency: increases significantly after thermal exposure at $1,000{ }^{\circ} \mathrm{C}$ for $500 \mathrm{~h}$ but drops dramatically when the thermal exposure temperature is increased to $1,100{ }^{\circ} \mathrm{C}$. However, under the condition of
$1,093{ }^{\circ} \mathrm{C} / 137 \mathrm{MPa}$, as shown in Fig. 4(d), the heat-treated samples have the longest lifetime, indicating that long-term thermal exposure reduces the creep lifetime of DD5 alloy, which is consistent with the results in Refs. [11, 12]. It is such a surprising result that under the condition of $1,038^{\circ} \mathrm{C} / 172 \mathrm{MPa}$, long thermal exposure at $1,000{ }^{\circ} \mathrm{C}$ for $500 \mathrm{~h}$ caused the creep lifetime improvement to $135 \mathrm{~h}$ from $98 \mathrm{~h}$ of the heat treated sample, increased by about $38 \%$, as shown in Fig. 4(c), which seemed to be not consistent with literature ${ }^{[14-15]}$. The above results indicate that DD5 alloy after long-term thermal exposure experiences a long steady state stage with a low strain rate.

Figure 5 shows the microstructure near the fracture of a creep-ruptured specimen under $1,038{ }^{\circ} \mathrm{C} / 172 \mathrm{MPa}$. It is found that not only in heat-treated state but also in long-term thermal exposure state, the cracks produced during creep tests are mainly located in the interdendritic regions. Although the single crystal superalloys have been solid solution heat 

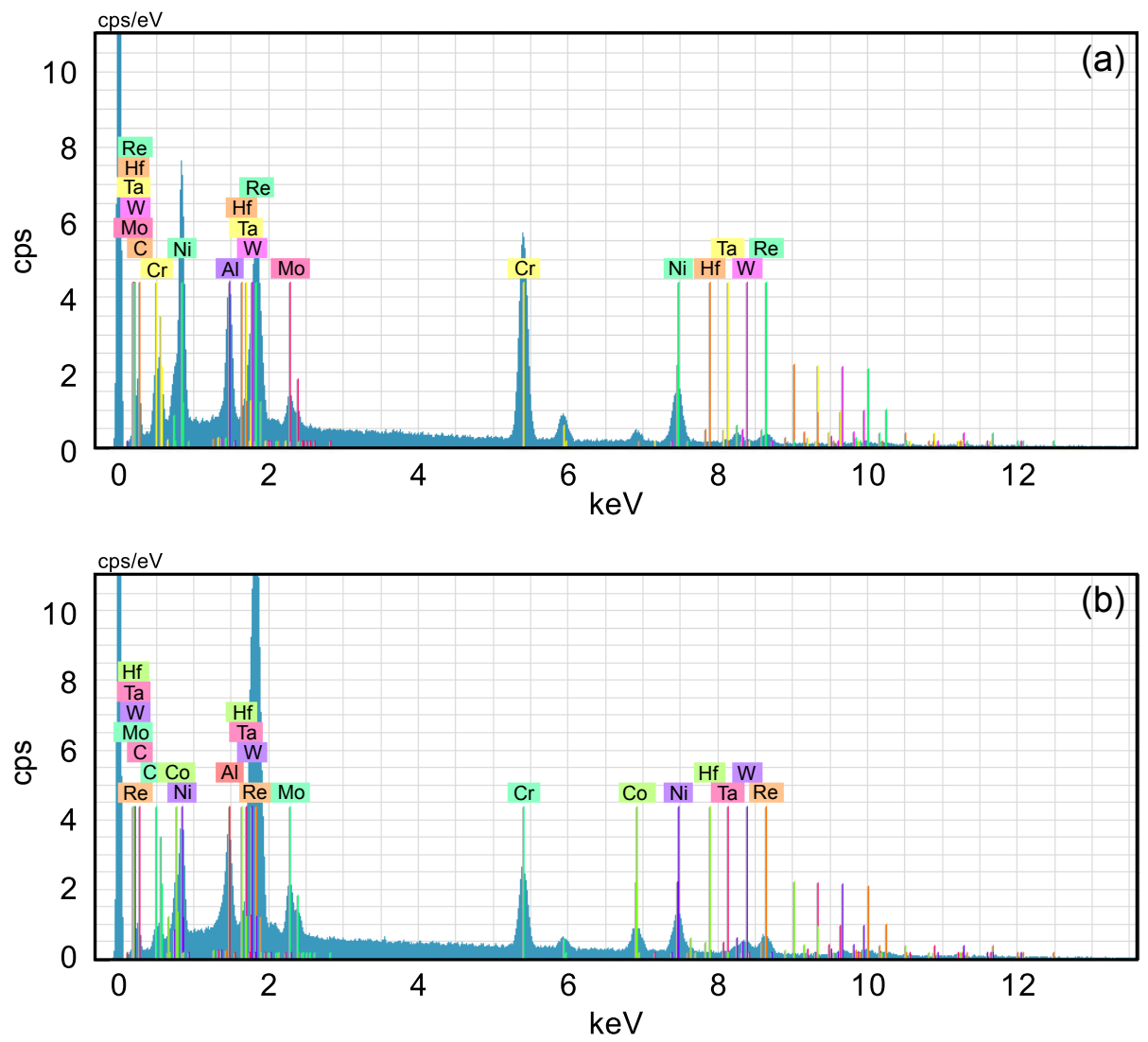

Fig. 3: EDS analysis of precipitated phases at different sites in single crystal superalloy after long-term thermal exposure at $1,000{ }^{\circ} \mathrm{C} / 500 \mathrm{~h}$ : (a) precipitates in interdendritic region; (b) precipitates in dendrite arm
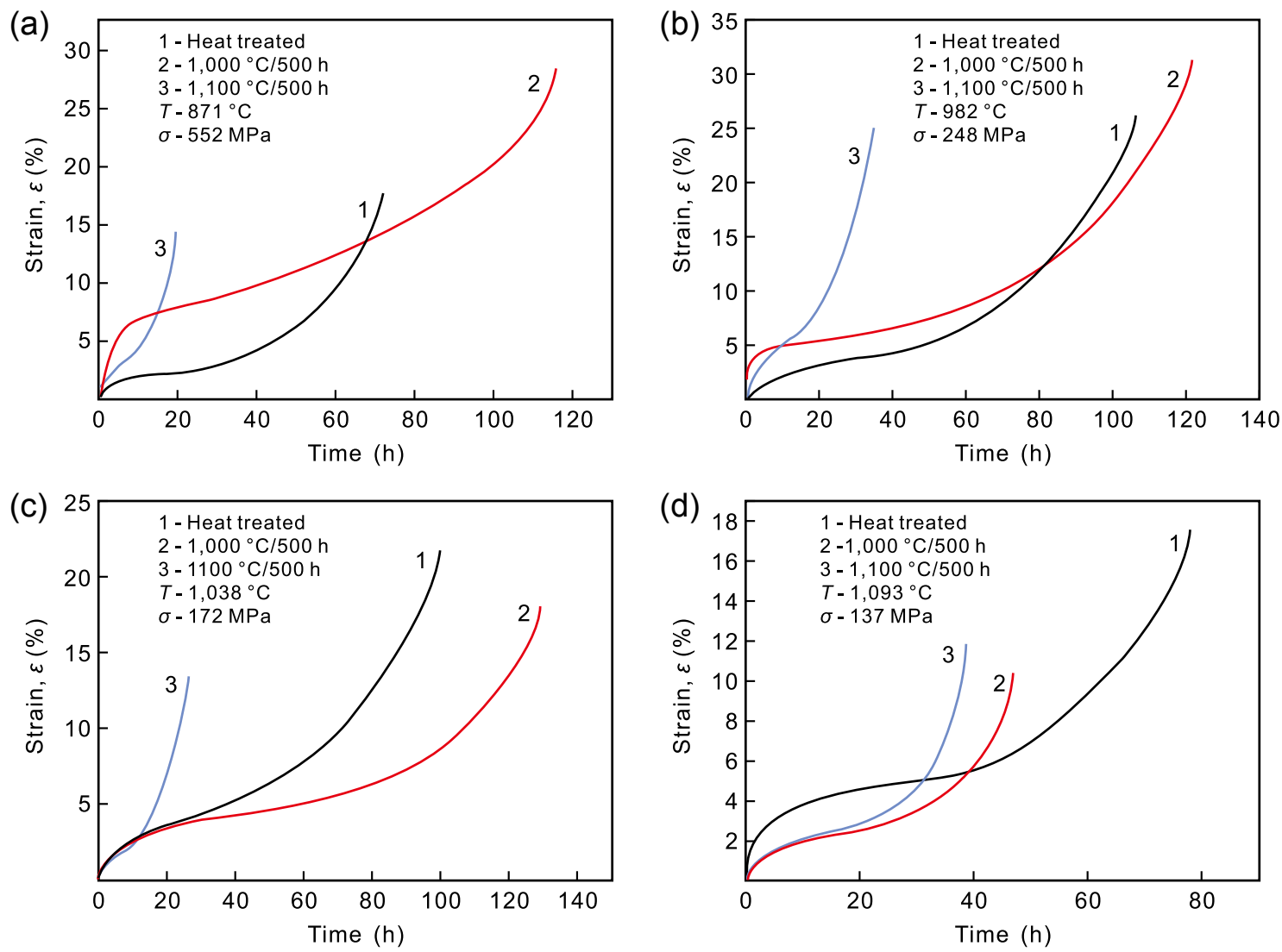

Fig. 4: Creep curves of DD5 alloy after heat treatment and long-term thermal exposure under different test conditions: (a) $871^{\circ} \mathrm{C} / 552 \mathrm{MPa}$; (b) $982{ }^{\circ} \mathrm{C} / 248 \mathrm{MPa}$; (c) $1,038^{\circ} \mathrm{C} / 172 \mathrm{MPa}$; (d) $1,093^{\circ} \mathrm{C} / 137 \mathrm{MPa}$ 

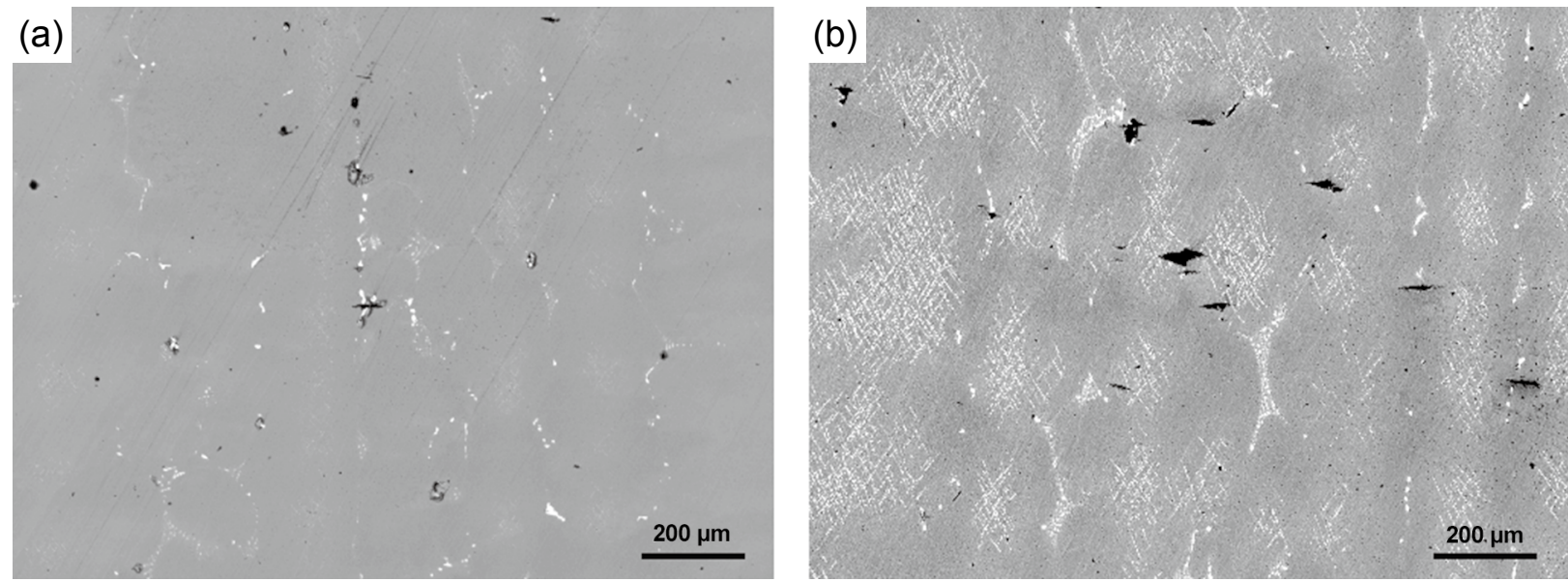

Fig. 5: Microstructures near the fracture of ruptured specimen under $1,038^{\circ} \mathrm{C} / 172 \mathrm{MPa}$ : (a) heat-treated state; (b) long-term thermal exposure at $1,000^{\circ} \mathrm{C}$ for $500 \mathrm{~h}$

treated, the dendritic segregation still cannot be eliminated thoroughly because of many refractory elements in the alloy. The microstructure in interdendritic regions is inhomogeneous including some undissolved MC carbides, subgrain boundaries and coarse $\gamma^{\prime}$ phases, so the interdendritic regions become the weak links of alloys. It can be seen that the long-term thermal exposure has no impact on the location of cracks initiation, so the strength in the interdendrite region determines the strength of the alloy. Therefore, the microstructure in the interdendritic regions was further studied. Figure 6 shows the microstructure in the interdendritic regions after creep tests under different conditions. From Fig. 6(a-c), it can be seen that there are many white granular phases in the interdendritic region, while not in Fig. 6(d). Because the white granular particles are rich in $\mathrm{Cr}$ and Re elements, they are speculated as $\mathrm{M}_{23} \mathrm{C}_{6}$ carbide, which will be identified in the following paragraph. As shown in Fig. 6(a, b), the $\gamma^{\prime}$ rafts are not regular in the interdendritic region, which causes the interdendritic region to become weak points. The
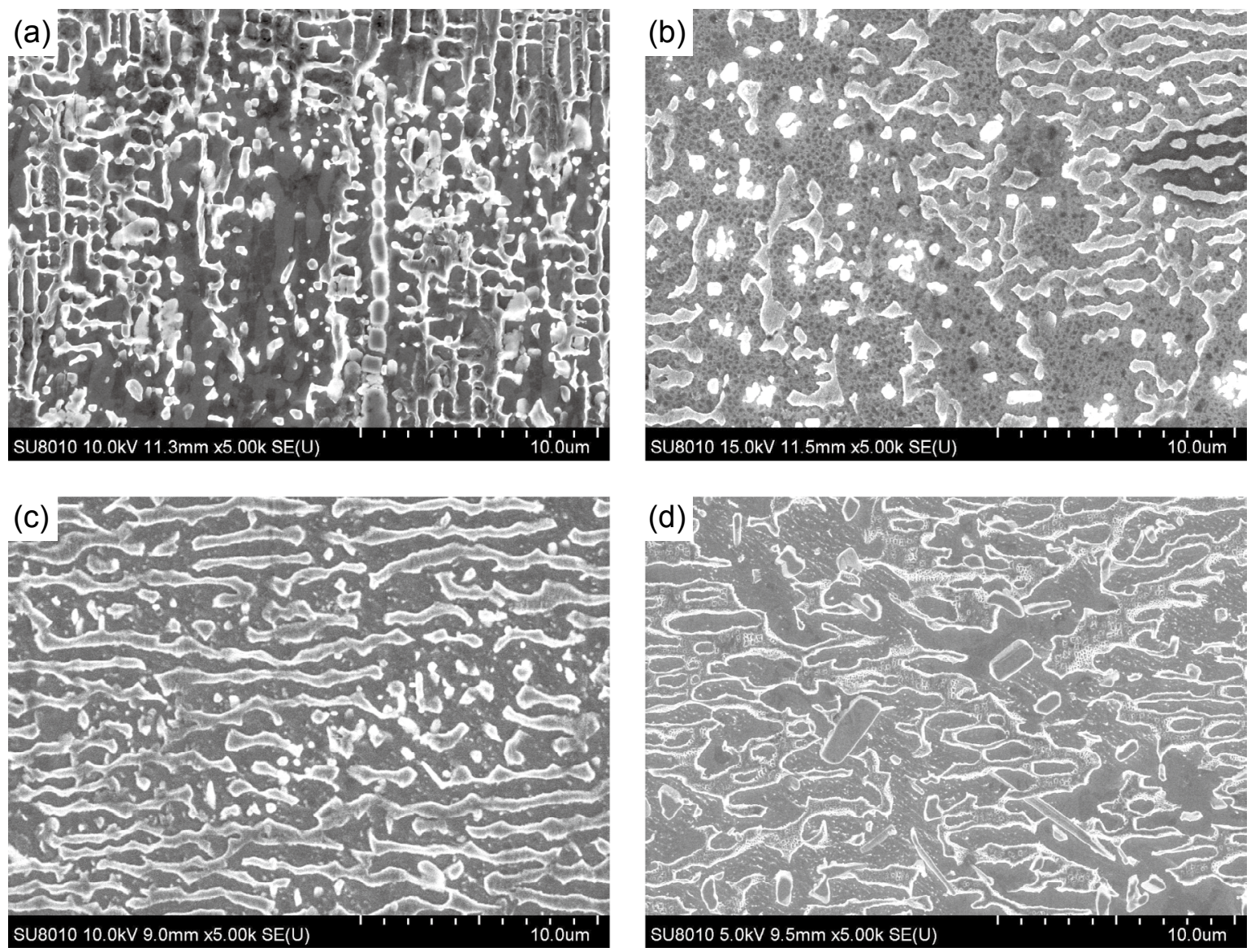

Fig. 6: Microstructures in interdendritic region after creep rupture tests at different conditions for alloy after long-term aging at $1,000{ }^{\circ} \mathrm{C}$ for $500 \mathrm{~h}$ : (a) $871^{\circ} \mathrm{C} / 552 \mathrm{MPa}$; (b) $982{ }^{\circ} \mathrm{C} / 248 \mathrm{MPa}$; (c) $1,038^{\circ} \mathrm{C} / 172 \mathrm{MPa}$; (d) $1,093^{\circ} \mathrm{C} / 137 \mathrm{MPa}$ 
granular carbide precipitated from $\gamma$ matrix can reinforce the weak areas by hindering the dislocation movement.

The dramatic prolongation of creep lifetime is contributed by the strengthening effect of precipitated fine particles in the interdendritic region during long-term thermal exposure, as shown in Fig. 7(a). The fine particles can hinder the dislocation movement and crack propagation, which are beneficial to the improvement of creep properties. The selected area electron diffraction pattern further determined the type of particle-like carbide to be $\mathrm{M}_{23} \mathrm{C}_{6}$-type carbide [Fig. 7(a,b)]. The zone axes can be labeled as $[001]_{\mathrm{M}_{23} \mathrm{C}_{6}} / /[001]_{\gamma^{\prime}}$ in the diffraction pattern. A picture of high-resolution TEM with coherent interface is shown in Fig. 7(c). The $\mathrm{M}_{23} \mathrm{C}_{6}$-type carbide has an FCC structure with an orientation relationship of $\left\langle 100>_{\mathrm{M}_{23} \mathrm{C}_{6}} / /<100\right\rangle_{\gamma^{\prime}}$ and $\{100\}_{\mathrm{M}_{23} \mathrm{C}_{6}} / /\{100\}_{\gamma^{\prime}}$ with the $\gamma^{\prime}$ phase. A fast fourier transform (FFT) filtered HAADF-STEM image of $\mathrm{M}_{23} \mathrm{C}_{6}$ carbide is shown in Fig. 7(d), which indicates the relationship of atomic arrangement in the $\mathrm{M}_{23} \mathrm{C}_{6}$-type carbide. The white bright spots represent the atomic column, which influences the distribution of atom number with the brightness of atomic column. Xiang et al. ${ }^{[14]}$ pointed out the refractory elements distributed in the bright atomic column are mainly Re (marked by yellow arrows) in Fig. 7(d), and Re prefers to substitute $\mathrm{Cr}$ in the $\mathrm{M}_{23} \mathrm{C}_{6}$-type carbides. The site preference of Re enhances the stability of $\mathrm{M}_{23} \mathrm{C}_{6}$-type carbide and makes the $\mathrm{M}_{23} \mathrm{C}_{6}$-type carbide become an effective strengthening phase in the alloy.
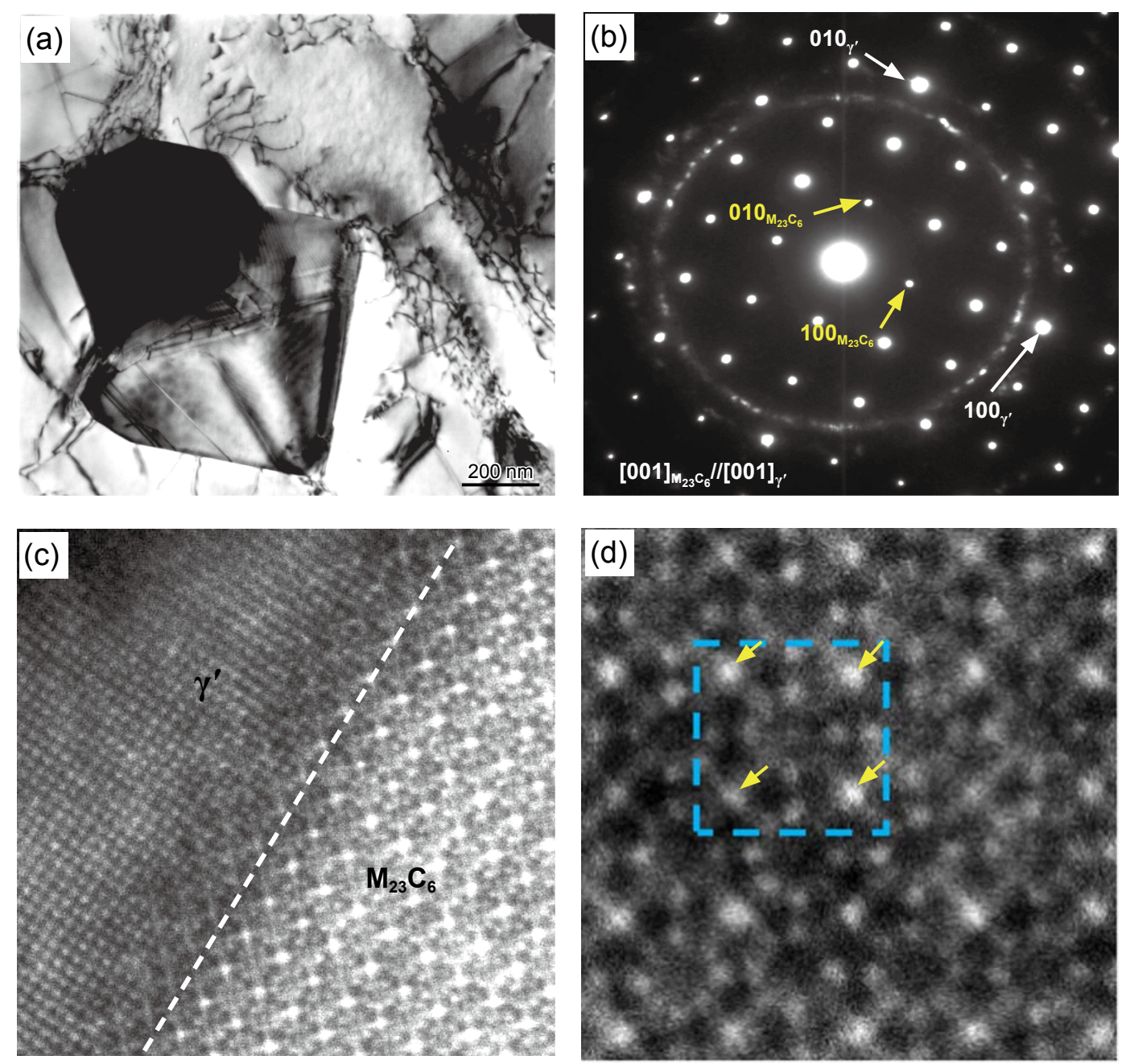

Fig. 7: Morphology and structure of $\mathrm{M}_{23} \mathrm{C}_{6}$ carbide formed in the thermal exposed specimen after creep tests under $982^{\circ} \mathrm{C} / 248 \mathrm{MPa}$ : (a) TEM image of $\mathrm{M}_{23} \mathrm{C}_{6}$ particle; (b) electron diffraction pattern; (c) HRTEM image of $M_{23} C_{6} / Y^{\prime}$ interface; (d) HAADF-STEM image of $M_{23} C_{6}$ carbide particle

The stable temperature of $\mathrm{M}_{23} \mathrm{C}_{6}$ carbide is between $870{ }^{\circ} \mathrm{C}$ and $1,050^{\circ} \mathrm{C}^{[15-16]}$, therefore, there is almost no $\mathrm{M}_{23} \mathrm{C}_{6}$ carbide in the ruptured specimen after creep test under $1,093{ }^{\circ} \mathrm{C} / 137 \mathrm{MPa}$ and in the specimen subjected to long-term thermal exposure at $1,100{ }^{\circ} \mathrm{C}$ for $500 \mathrm{~h}$. As a result, the creep lifetime after longterm exposure at $1,000{ }^{\circ} \mathrm{C}$ for $500 \mathrm{~h}$ dropped dramatically under $1,093^{\circ} \mathrm{C} / 137 \mathrm{MPa}$ and after long-term thermal exposure at $1,100{ }^{\circ} \mathrm{C}$ for $500 \mathrm{~h}$.

\section{Conclusions}

The effect of long-term thermal exposure on the microstructure and creep properties of DD5 single crystal nickel-based superalloy was studied. The following conclusions can be drawn from the above results and discussions:

(1) After long-term thermal exposure at $1,000{ }^{\circ} \mathrm{C}$ for $500 \mathrm{~h}$, cubic $\gamma^{\prime}$ particles are coarsened and turned to link together; 
TCP phases precipitate mainly in the dendritic arm region and $\mathrm{M}_{23} \mathrm{C}_{6}$ carbides mainly precipitate in the interdendritic region.

(2) After long-term thermal exposure at $1,100{ }^{\circ} \mathrm{C}$ for $500 \mathrm{~h}$, $\gamma^{\prime}$ particles gather severely, a small quantity of TCP phases precipitate in the dendrite arm, and no $\mathrm{M}_{23} \mathrm{C}_{6}$ carbide precipitates in the interdendritic region.

(3) Compared with the sample after heat treatment, the creep properties of DD5 alloy after the long-term exposure at $1,000{ }^{\circ} \mathrm{C}$ for $500 \mathrm{~h}$ under the testing conditions of $1,038^{\circ} \mathrm{C} /$ $172 \mathrm{MPa}, 982{ }^{\circ} \mathrm{C} / 248 \mathrm{MPa}$ and $871{ }^{\circ} \mathrm{C} / 552 \mathrm{MPa}$ are improved as a result of the formation of the secondary $\mathrm{M}_{23} \mathrm{C}_{6}$ in the interdendritic region.

(4) The creep lifetime of $1,000{ }^{\circ} \mathrm{C}$ thermally exposed sample under the conditions of $1,093{ }^{\circ} \mathrm{C} / 137 \mathrm{MPa}$ is lower than that of heat-treated state. Thermal exposure at $1,100{ }^{\circ} \mathrm{C}$ for $500 \mathrm{~h}$ causes the creep lifetime to drop drastically.

\section{Acknowledgement}

This study was funded by the Key Laboratory of Advanced High-temperature Structural Materials for National Defense Science and Technology, China (No: 6142903180104).

\section{References}

[1] Erickson G L. Single crystal nickel-based superalloy. U.S. Patent No. 5366695, 1994.

[2] Erickson G L. Single crystal nickel-based superalloy. U.S. Patent No. 5540790, 1996.

[3] Walston W S, Hara, K S O, Ross E W, et al. Rene' N6: Third generation single crystal superalloy. Superalloys, 1996: 27-34.

[4] Gao S, Liu Z Q, Cui J P, et al. In situ transformation from $P$ phase to $\mu$ phase in rhenium-containing single crystal superalloy during thermal exposure. Philosophical Magazine Letters, 2017, 97: 188-196.

[5] Rehman H, Durst K, Neumeier S, et al. Nanoindentation studies of the mechanical properties of the $\mu$ phase in a creep deformed Re containing nickel-based superalloy. Materials Science and Engineering A, 2015, 634: 202-208.
[6] Liu L R, Jin T, Zhao N R, et al. Formation of carbides and their effects on creep of a Ni-base single crystal superalloy. Materials Science and Engineering A, 2003, 361(1-2): 191-197.

[7] Kim K H, Withey P A. Microstructural investigation of the formation and development of topologically close-packed phases in a 3rd generation nickel-base single crystal superalloy. Advanced Engineering Materials, 2017, 19(6): 1700041.

[8] Tin S, Pollock T M. Phase instabilities and carbon additions in single-crystal nickel-base superalloys. Materials Science and Engineering A, 2003, 348 (1-2): 111-121.

[9] Wen T, Li J G, Liu L R, et al. Effect of long-term aging on microstructure evolution and creep properties of Ni-based single crystal superalloy. Rare Metal Materials \& Engineering, 2012, 41(2): 230-234.

[10] Zhang $\mathrm{H}$, Liang $\mathrm{Y} \mathrm{F,} \mathrm{Ru} \mathrm{Y,} \mathrm{et} \mathrm{al.} \mathrm{Effect} \mathrm{of} \mathrm{thermal} \mathrm{exposure}$ on the stress-rupture life and microstructure of a low Recontaining single crystal alloy. Progress in Natural Science: Materials International, 2015, 25(1): 84-89.

[11] Liu J L, Jin T, Yu J J, et al. Effect of thermal exposure on creep properties of a $\mathrm{Re}$ bearing $\mathrm{Ni}$ base single crystal superalloy. Materials Science and Engineering A, 2010, 527: 890-897.

[12] Yin H F, Gao Y M, Gu Y F. Effects of long term thermal exposure on microstructure and mechanical property evolution of a new wrought $\mathrm{Ni}-\mathrm{Fe}$ based superalloy. Materials Design, 2016, 105: 66-74.

[13] Guo Jianting. Materials science and engineering for superalloys. Science Press, Beijing China, 2008. (In Chinese)

[14] Xiang S S, Mao S C, Shen Z J, et al. Site preference of metallic elements in $\mathrm{M}_{23} \mathrm{C}_{6}$ carbide in a Ni-based single crystal superalloy. Materials \& Design, 2017, 129: 9-14.

[15] Wang J, Zhou L Z, Sheng L Y, et al. The microstructure evolution and its effect on the mechanical properties of a hot-corrosion resistant $\mathrm{Ni}$ based superalloy during long-term thermal exposure. Materials \& Design, 2012, 39: 55-62.

[16] Huang M, Yang X Y, Liu W W, et al. Precipitation characteristics of a nickel-based single-crystal superalloy after long-term thermal exposure. International Journal of Materials Research, 2018, 109(9): 811-818. 